\title{
AVALIAÇÃO QUALITATIVA DE IMPACTOS AMBIENTAIS CONSIDERANDO AS ETAPAS DE LIMPEZA E PREPARO DO TERRENO EM PLANTIOS FLORESTAIS NO NORDESTE PARAENSE ${ }^{1}$
}

\author{
Márcia Nágem Krag², Rodrigo Silva do Vale ${ }^{3}$, Elias Silva ${ }^{4}$, Francisco de Assis Oliveira ${ }^{3}$, Marcos André \\ Piedade Gama ${ }^{3}$ e Paulo de Tarso Eremita da Silva ${ }^{3}$
}

\begin{abstract}
RESUMO - Este trabalho apresenta os resultados da avaliação qualitativa de impactos ambientais na etapa de implantação florestal, considerando-se as atividades de limpeza e preparo do terreno, por meio da aplicação dos métodos de matriz de identificação e interação de impactos, da lista descritiva (checklist) e da combinação/ ponderação de atributos. Tal avaliação foi feita com base na identificação e caracterização qualitativa dos impactos ambientais, cujas metodologias possibilitaram a visualização rápida e hierarquizada dos impactos. Através dessa matriz, evidenciaram-se 348 possíveis relações de impactos (capacidade total da matriz), das quais 304 (87,6\%) foram identificadas, em que 209 impactos (60,05\%) recaíram sobre o meio biofísico e 95 (27,31\%) sobre o meio socioeconômico. Dos 209 impactos no meio biofísico, todos apresentaram valor negativo, evidenciando-se ser esse o compartimento ambiental mais impactado negativamente quando da realização das atividades de limpeza e preparo do terreno. Já, dos 95 impactos no meio socioeconômico, 72 (75,78\%) foram de valor positivo e 23 (24,21\%) de valor negativo, demonstrando que o meio socioeconômico é o compartimento ambiental mais afetado positivamente por ocasião da realização das atividades. Foram identificados os impactos ambientais positivos e negativos mais significantes que, com a combinação/ponderação de atributos, mostraram ser, em sua maioria, de significância média local e regional. Todos os impactos evidenciados apresentaram temporalidade no curto prazo, evidenciando estarem sobre o alcance quanto ao diagnóstico e gestão ambiental adequados. Os resultados contribuem e reafirmam a necessidade de se instituir o processo de avaliação de impactos ambientais na rotina técnico-administrativa da empresa como instrumento de gestão ambiental.
\end{abstract}

Palavras-chave: Reflorestamento; Impacto ambiental; Diagnóstico ambiental.

\section{QUALITATIVE EVALUATION OF ENVIRONMENTAL IMPACTS CONSIDERING THE STAGES OF CLEANING AND PREPARATION OF THE AREAS OF FOREST PLANTATIONS IN THE NORTHEASTERN PARÁ STATE}

\begin{abstract}
This study presents the results of qualitative assessment of environmental impacts on the forest stage of implementation, considering the activities of cleaning and preparation of the land, through the application of matrix methods of identification and interaction impacts, descriptive list (checklist) and the combination/ weight attributes. This assessment was based on the identification and qualitative characterization of environmental impacts, whose methodologies allowed the fast and hierarchical view of the impacts. Through the array was revealed a possible relationship of 348 impacts (total capacity of the matrix), and of these 304 (87.6\%) were identified, which impacts 209 (60.05\%) relapsed on the biophysical environment and 95 (27, 31\%) on the socioeconomic environment. Among the 209 impacts on the biophysical environment, all showed a
\end{abstract}

\footnotetext{
${ }^{1}$ Recebido em 28.11.2011 aceito para publicação em 06.08.2013.

${ }^{2}$ Programa de Pós-Graduação em Ciências Agrárias na Universidade Federal Rural da Amazônia, UFRA, Brasil. E-mail: <marcia_krag@hotmail.com>.

${ }^{3}$ Universidade Federal Rural da Amazônia, UFRA, Brasil. E-mail: <rodrigo.vale@ufra.edu.br>,<francisco.oliveira@ufra.edu.br>, $<$ marcos.andre@ufra.edu.br>e < paulo.eremita@ufra.edu.br>.

${ }^{4}$ Departamento de Engenharia Florestal da Universidade Federal de Viçosa, UFV, Brasil.E-mail: <eshamir@ufv.br>.
} 
negative value, suggesting that this is the most negatively impacted environmental compartment when carrying out the activities of cleaning and preparing the ground. From the 95 socioeconomic impacts, 72 (75.78\%) had a positive value and $23(24.21 \%)$ had a negative value, showing that the socioeconomic environment is the most positively affected of the environmental compartments when carrying out the activities. Were identified the most significant positive and negative environmental impacts that, with the combination / balance of attributes showed to be of average local and regional significance. All impacts evidenced presented temporality in short-term, showing that they are on the scope to the diagnosis and appropriate environmental management. The results contribute to and reaffirm the need to establish the process of environmental impact assessment in technical and administrative businesses routine as a tool in environmental management.

Keywords: Reforestation; Environmental impact; Environmental diagnosis.

\section{INTRODUÇÃO}

Antes da década de 1970, os empreendedores preocupavam-se com a viabilidade técnico-econômica dos seus projetos, cujo objetivo fundamental era produzir mais ao menor preço. $\mathrm{O}$ meio ambiente era considerado inesgotável, tanto no que se referia ao fornecimento das matérias-primas quanto ao seu potencial de absorver os resíduos produtivos e até o resíduo do próprio produto após o seu consumo ou o término da sua vida útil (STAMM, 2003). No entanto, a partir da Conferência das Nações Unidas de Estocolmo, realizada em junho de 1972, os problemas ambientais passaram a ser encarados com maior atenção, principalmente em virtude da exigência de Avaliações de Impactos Ambientais (AIA) para a concessão de empréstimos internacionais (ANDREAZZI; ANDRADE, 1990). Dessa forma, passou-se a incluir um cuidado maior com a variável ambiental durante o desenvolvimento dos projetos, em que, segundo $\mathrm{La}$ Rovere (2001), foi-se incorporando as questões ambientais aos processos de decisões das empresas.

Nesse contexto, Lima e Mendes (2007) ressaltaram que, atualmente, as empresas florestais têm tomado importantes decisões em relação aos aspectos ambientais, como a água, a erosão do solo, a paisagem, a conservação da biodiversidade e outros aspectos, que passaram a fazer parte das preocupações da indústria florestal, principalmente em virtude da grande influência da opinião pública com relação à implantação de florestas de rápido crescimento.

No que se refere à implantação florestal, ela compreende as operações que vão desde o reconhecimento e limpeza da área, infraestruturas, preparo do solo, plantio e tratos culturais até o estabelecimento da floresta, que se dá no terceiro ou quarto ano, dependendo das condições edafoclimáticas das áreas de plantios (COUTO et al., 2002).
Do ponto de vista ambiental, o reflorestamento, em geral, é atividade muito polêmica, em razão de uma opinião pública generalizada que lhe atribui efeitos ecológicos adversos, relacionados com o consumo de água e perdas de solo e de nutrientes, constituindo-se nos chamados efeitos ecológicos do reflorestamento. Para Lima e Mendes (2007), esses efeitos podem ser reais, ou seja, estão presentes em muitos dos projetos de reflorestamento feitos na fase inicial dos incentivos fiscais no Brasil. Todavia, esses efeitos ecológicos têm característica extremamente interessante: eles podem ser minimizados, ou seja, podem estar ao alcance do controle do profissional florestal, através da adoção de práticas ambientalmente sustentáveis de manejo florestal.

Nesse sentido, em razão de se compreender as inter-relações inerentes aos processos, ações, efeitos ambientais e modificações do meio, as evidências de possíveis impactos podem contribuir para direcionar o gerenciamento. Com isso, subsidia a iniciativa da tomada de decisões quanto à gestão sustentável do ambiente e auxilia na incorporação das questões ambientais como parte integrante dos processos inerentes à implantação florestal.

Diante do exposto, foram avaliados qualitativamente os impactos ambientais decorrentes das atividades empregadas na etapa de implantação florestal, com ênfase nas atividades de limpeza e preparo do terreno, considerando-se o meio ambiente em seus aspectos biofísicos e socioeconômicos.

\section{MATERIAL E MÉTODOS}

O estudo foi implementado nas áreas de reflorestamento da empresa florestal CIKEL BRASIL VERDE MADEIRAS LTDA. (CKBVM), no Município de Paragominas, localizado entre os meridianos $2^{\circ} 25^{\prime}$ 
e $3^{\circ} 48^{\prime}$ de latidudes Sul e $46^{\circ} 25^{\prime}$ e $48^{\circ} 53^{\prime}$ de longitude Oeste, a 310 km de Belém, mesorregião Sudeste do Estado do Pará (CREPANI et al., 2005).

Os procedimentos de avaliação ambiental adotados foram voltados para avaliação qualitativa de impactos ambientais, considerando as atividades (ações) empregadas na etapa de implantação florestal, com ênfase nas atividades de limpeza e preparo do terreno, visando à avaliação global dos efeitos das atividades sobre os fatores dos meios biofísicos e socioeconômicos.

Por meio de abordagem multidisciplinar, os levantamentos dos dados citados compreenderam a coleta de dados secundários disponíveis na empresa CKBVM (com engenheiros florestais, coordenadores do projeto, gerentes de meio ambiente, funcionários locais, entre outros) e em referências bibliográficas específicas consultadas em meios impressos e eletrônicos publicados, bem como em dados gerados pela própria empresa constantes em seus procedimentos operacionais (não publicados). Já os dados primários foram coletados a partir das visitas de campo, acompanhando a execução das atividades, e com observação dos eventos específicos do meio ambiente in loco, coletando informações sobre fatores/indicadores do meio, levantados com finalidade específica para avaliação dos impactos ambientais (AIA). Esse levantamento ocorreu por meio de aplicação de checklist descritivo e posteriormente com a montagem da matriz de interação de impactos e a combinação e ponderação de atributos (critérios qualitativos).

Segundo Freitas et al. (2007), o estudo do impacto ambiental por meio de checklist descritivo e da matriz de interação de impactos mostra-se como alternativa eficiente na avaliação das alterações nos compartimentos biofísicos e antrópicos, uma vez que permitem caracterizar a problemática ambiental de forma ilustrativa, possibilitando, assim, o norteamento mais expressivo em termos de controle desses parâmetros ambientais.

Nesse sentido, a matriz foi elaborada de acordo com a metodologia proposta por Silva (1994), sendo elencadas nas linhas as atividades impactantes que ocorrem na etapa de implantação florestal (considerando a limpeza e preparo do terreno) e nas colunas, os fatores ambientais relevantes do meio biofísico (ar, recurso edáfico, recurso hídrico, flora terrestre e aquática, fauna terrestre e aquática) e do meio socioeconômico (histórico de ocupação, paisagem, emprego, renda, desenvolvimento regional, capacitação, saúde, fixação do homem na terra). Para o preenchimento da matriz, considerou-se a classificação qualitativa dos impactos, utilizando critérios para caracterização das alterações ambientais ocorridas. Tais critérios foram definidos e igualmente adotados por Silva (1994), Ludke (2000), Arruda (2000), Brito (2001), Barbosa e Dupas (2006) e Lara e Peters (2006), em que se caracterizaram os impactos em função do valor, ordem, espaço, tempo, dinâmica e plástica. Para auxiliar a interpretação dos resultados, os atributos avaliados foram combinados e ponderados.

A combinação de atributos foi descrita com a ajuda de uma escala numérica, em que cada atributo recebeu um peso resultante da soma ponderada (multiplicação do valor numérico de cada atributo por seu peso), que reflete diretamente na significância dos impactos em termos de análise qualitativa. Para essa avaliação, atribui-se a seguinte escala de significância: pesos de 0-20: significância pequena; de 21-35: significância média; e pesos acima de 36, significância grande.

Diante do exposto, a identificação e caracterização qualitativa dos impactos ambientais foram feitas a partir da utilização do método de checklist descritivo e da matriz de interação de impactos que, de acordo com Lelles et al. (2005), consiste no vislumbramento e na listagem de consequências (impactos ambientais), quando se considera o potencial transformador do meio ambiente e de suas causas (atividades impactantes) conhecidas.

Cabe ressaltar que os procedimentos metodológicos adotados estão entre os métodos mais utilizados em AIA nos dias atuais e vêm-se aprimorando com a finalidade de tornar as avaliações de impactos mais eficientes. Isso porque facilitam as análises de grande número de informações apresentadas e a qualificação e, ou, quantificação dos impactos, o que justifica a escolha deles para o referido estudo.

\section{RESULTADOS}

\subsection{Identificação e descrição das atividades impactantes desenvolvidas na fase de implantação florestal, considerando a etapa de limpeza do terreno através de checklist}

- Aceiramento: nesta atividade, o operador de trator-esteira habilitado percorre os limites sinalizados com fitas plásticas amarradas aos galhos. Assim, o trator equipado com uma lâmina empurradora e, ou, 
lisa, projetada para corte e nivelamento, respectivamente, é usado durante o dia para a retirada da vegetação e à noite aplaina a faixa, formando, assim, o aceiro que servirá também de estrada para acesso à área.

- Combate às formigas: no início da implantação, a atividade de combate às formigas é realizada especificamente nas bordaduras das áreas, aplicando-se iscas granuladas nos olheiros de formigas (saúvas), com distância equivalente a $30 \mathrm{~m}$ da área. Após o plantio, é aplicado formicida nos olheiros de formigas-de-fogo e saúvas.

- Quebra de juquira: esta atividade é realizada com o intuito de facilitar a retirada do excesso de vegetação da área a ser plantada. São utilizados dois tratoresesteira com peso e potência equivalentes, unidos na barra de tração pelas extremidades por uma corrente (correntagem). Esses tratores adentram paralelamente na área previamente selecionada, arrastando a corrente, que por sua vez quebra a vegetação. Têm-se a opção ainda da utilização individual de um trator-esteira equipado com ancinho, que empurra uma tora reta de 10 a 15 m sobre a vegetação.

- Enleiramento: na referida atividade, um tratoresteira equipado preferencialmente com um ancinho, a partir da bordadura, empilha superficialmente (para minimizar a retirada de porções férteis da superfície do solo) a vegetação quebrada, formando leiras a cada $50 \mathrm{~m}$ de distância.

- Queima controlada: após o empilhamento e perda de umidade dos resíduos vegetais, dois ajudantes florestais e um operador com trator agrícola acoplado a uma pipa d'água realizam, em horários de menor incidência de vento (ao entardecer), a queima das leiras. Durante a queima, uma equipe realiza a vigilância, a fim de evitar a propagação indesejada do fogo.

- Desenleiramento: após o esfriamento das leiras queimadas, o trator-esteira acoplado a um ancinho desfaz as leiras, espalhando o material carbonizado sobre o solo.

- Destoca: nesta atividade, o operador do tratoresteira com a lâmina inclinada em um ângulo de $30^{\circ}$ utiliza a ponta do implemento para desenterrar e cortar as raízes dos tocos. Estes são arrancados do solo e deixados na superfície para serem retirados da área posteriormente.
- Limpeza da área ou coivara: na atividade de limpeza da área, a equipe de ajudantes florestais, com o auxílio de facões, realiza a limpeza da área (coivara), retirando tocos e varas que ficaram após o enleiramento e os amontoam para posteriormente serem queimados.

\subsection{Identificação e descrição das atividades impactantes desenvolvidas na fase de implantação florestal, considerando a etapa de preparo do terreno através de checklist}

- Talhonamento: utilizando o trator-esteira acoplado a uma lâmina, faz-se a abertura de uma estrada principal com $8 \mathrm{~m}$ de largura e estradas secundárias com 6 m de largura. Essas estradas fazem a delimitação dos quadrantes com área de 500 x 500 m, ou 25 ha.

- Gradagem: após a limpeza da área (retirada da vegetação), um trator-agrícola, skider ou tratoresteira de menor potência (D50 ou D41), acoplado a uma grade aradora pesada, inicia, a partir das bordaduras, a gradagem da área puxando a grade aradora no sentido carrossel. Dessa forma, realiza-se um corte com profundidade de 15 a $20 \mathrm{~cm}$ para revolvimento das camadas superficiais do solo. Verifica-se a declividade do solo, evitando corte morro abaixo. Para planear o terreno, finaliza-se a gradagem com uma grade niveladora, que faz a quebra dos torrões eventuais formados pela grade aradora pesada.

- Calagem: com base em análises de solo e nas recomendações agronômicas, faz-se, quando necessário, a calagem da área. Para essa atividade, utilizam-se um trator agrícola e um distribuidor de calcário. O implemento é regulado de acordo com a quantidade de calcário a ser lançado, abastecido com uma carregadeira ou com pás. O trator percorre a área distribuindo uniformemente o calcário sobre o solo.

- Subsolagem: com a área preparada e o espaçamento entre linhas definido, faz-se primeiramente o balizamento de acordo com a topografia do terreno e, preferencialmente, no sentido leste-oeste. Para isso, são fincadas estacas que servirão como balizas a cada $50 \mathrm{~m}$, em uma reta com comprimento de acordo com o talhonamento da área. Posteriormente, regula-se o subsolador para distribuição de fosfato reativo baseado nas análises de solo. O operador de trator agrícola alinha o trator e o subsolar na reta balizada, fincando o escarificador no solo e realizando o corte e a distribuição do fosfato na profundidade determinada $(55-60 \mathrm{~cm})$. 
O processo é repetido até a finalização da última linha. Para controle, são coletadas amostras de profundidade, espaçamento e regulagem do implemento com o auxílios de uma régua de ferro ou madeira, trena e balança.

\subsection{Identificação e caracterização dos impactos ambientais através da matriz de interação de impactos}

A matriz de interação de impactos (Figura 1), considerando as atividades impactantes identificadas na fase de implantação florestal e enfatizando as atividades de limpeza e preparo de terreno, apresentou 12 atividades que, multiplicadas pelo número de 29 fatores ambientais selecionados, perfizeram um total de 348 possíveis relações de impactos (capacidade total da matriz de interação). Desse total, foram identificados 304 (87,6\%), em que 209 impactos (60,05\%) recaíram sobre o meio biofísico e 95 (27,31\%) sobre o meio socioeconômicos. As demais 44 células não apresentaram nenhuma relação de impactos, correspondendo a $12,64 \%$ da capacidade total.

Em relação aos fatores do meio, do total de 252 possíveis relações de impactos no meio biofísico, foram evidenciados 209 impactos (83,00\%). As outras 43 $(17,00 \%)$ células não apresentaram relações de impactos.

Dos 209 (83,00\%) impactos evidenciados no meio biofísico, todos são de valor negativo, evidenciando ser este o compartimento do meio ambiente mais impactado negativamente quando da realização das atividades de limpeza e preparo do terreno.

No meio socioeconômico, do total de 96 possíveis relações de impactos, foram evidenciados 95 impactos, correspondente a 98,96\% de sua capacidade. Apenas uma célula (1,04\%) não apresentou relação de impacto.

Dos 95 (98,96\%) impactos evidenciados no meio socioeconômico, 72 (75,78\%) foram de valor positivo e 23 impactos (24,21\%), de valor negativo, demonstrando que o meio socioeconômico é o compartimento mais afetado positivamente quando da realização das atividades. Apenas uma célula $(0,01 \%)$ não apresentou relação de impacto.

Todos os impactos evidenciados, tanto no meio biofísico (209) quanto no socioeconômico (95), apresentam temporalidade em curto prazo, considerando que todos surgem na etapa de implantação florestal. Isso reforça a importância da atuação dos profissionais na execução das atividades, quanto à gestão ambiental eficiente, que leve em consideração as potencialidades e limitações do meio, evitando a degradação ambiental e contribuindo para o desenvolvimento das atividades florestais de forma sustentável.

Com o intuito de facilitar a interpretação de grande número de atributos avaliados através da matriz de interação, cujas características se assemelhavam em muitos dos impactos gerados. Os demais atributos foram combinados e ponderados, obedecendo a uma ordem segundo sua importância/significância para o critério de avaliação (Tabela 1). Dessa forma, através da combinação e ponderação, os atributos mais importantes recebem maiores pesos. Nesse sentido, os resultados das análises, considerando os fatores ambientais no meio biofísico e socioeconômico, demonstraram que:

\section{A) Meio Biofísico (físico + biótico)}

- Sobre o Fator Ambiental/Ar, todos os impactos apresentaram valor de significância entre 0-18, portanto caracterizando-se como de significância pequena (Figura 2).

- Sobre o Fator Ambiental/Recurso Edáfico, todos os impactos apresentaram valor de significância entre 02-27, portanto caracterizando-se como de significância média (Figura 2).

- Sobre o Fator Ambiental/Recurso Hídrico, todos os impactos apresentaram valor de significância entre 0-30, portanto caracterizando-se como de significância média (Figura 2).

- Sobre o Fator Ambiental Flora (Figura 3), em relação à Flora Aquática, todos os impactos apresentaram valor de significância entre 18-33, portanto caracterizando-se como de significância média. Quanto à Flora Terrestre, todos os impactos apresentaram valor de significância entre 0-34, caracterizando-se também como de significância média.

- Sobre o Fator Ambiental Fauna (Figura 3), em relação à Fauna Aquática, todos os impactos apresentaram valor de significância entre 21-30, caracterizando-se, portanto, como de significância média. Sobre a Fauna Terrestre, todos os impactos apresentaram valor de significância entre 02-09, caracterizando-se como de significância pequena.

\section{B) Meio Socioeconômico}

Sobre o Meio Socioeconômico (Figura 4) dos Impactos Positivos (+), todos apresentaram valor de significância entre 55-66, portanto caracterizando-se 


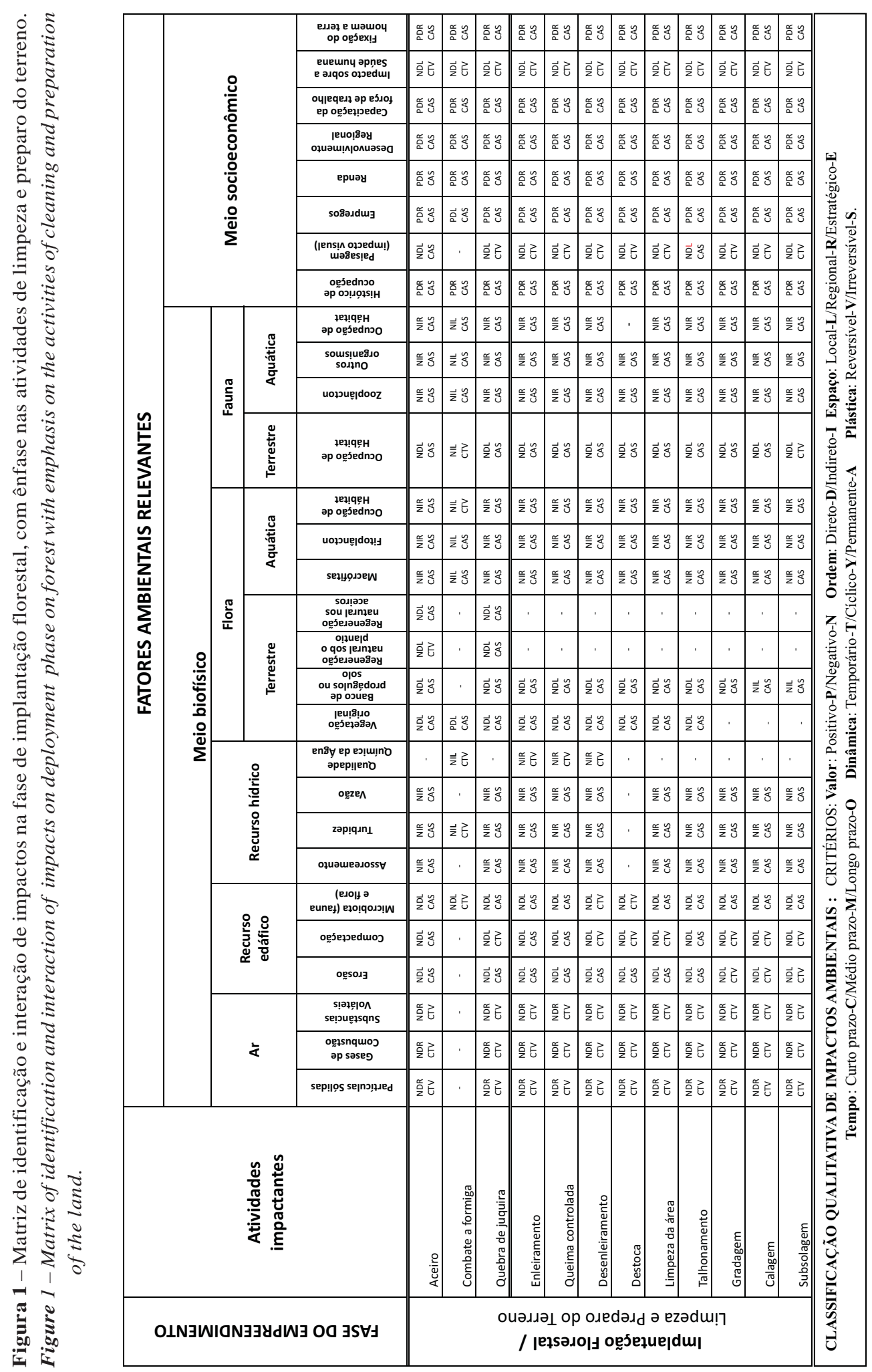


Tabela 1 - Combinação dos atributos (critérios qualitativos) e ponderação em pesos numéricos.

Table 1 - Combination of attributes (qualitative criteria) and weighting in numerical weights.

\begin{tabular}{cl}
\hline Pesos & Combinação dos critérios qualitativos \\
\hline 0 & $\begin{array}{l}\text { O impacto não ocorre em alguma das etapas } \\
\text { de limpeza/preparo do terreno }\end{array}$ \\
1 & Local/direto-indireto/reversível/magnitude baixa \\
2 & Local/direto-indireto/reversível/magnitude média \\
3 & Local / direto-indireto / reversível / magnitude alta \\
4 & Regional / direto-indireto / reversível / magnitude baixa \\
5 & Regional / direto-indireto / reversível / magnitude média \\
6 & Regional / direto-indireto / reversível / magnitude alta \\
7 & Local / direto-indireto / irreversível / magnitude baixa \\
8 & Local / direto-indireto / irreversível / magnitude média \\
9 & Local / direto-indireto / irreversível / magnitude alta \\
10 & Regional / direto-indireto / irreversível / magnitude baixa \\
11 & Regional / direto-indireto / irreversível / magnitude média \\
12 & Regional / direto-indireto / irreversível / magnitude alta
\end{tabular}

Fonte: adaptado de BARBOSA e DUPAS (2006).

Source: adapted from BARBOSA e DUPAS (2006).

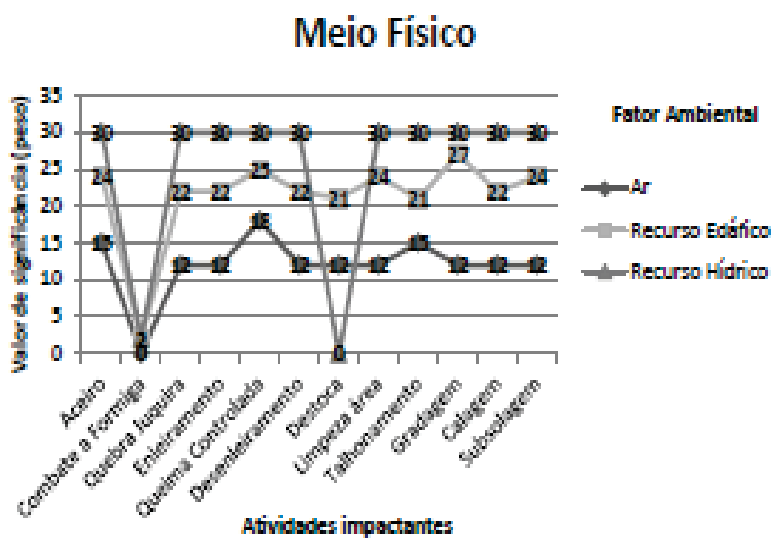

Figura 2 - Escala de significância sobre o ar, sobre o recurso edáfico e sobre o recurso hídrico.

Figure 2 - Figure 2 - Scale of significance on ther air, on edaphic resource and on the water resource

como de significância grande. Já com relação aos Impactos Negativos (-), todos apresentaram valor de significância entre 01-11, caracterizando-se, dessa forma, como de significância pequena.

\subsection{Identificação das atividades que receberam maiores pesos, quando da soma total na combinação e ponderação dos atributos}

Das 12 atividades, em que oito estão relacionadas à limpeza do terreno (aceiro, combate à formiga, quebra de juquira, enleiramento, queima controlada,

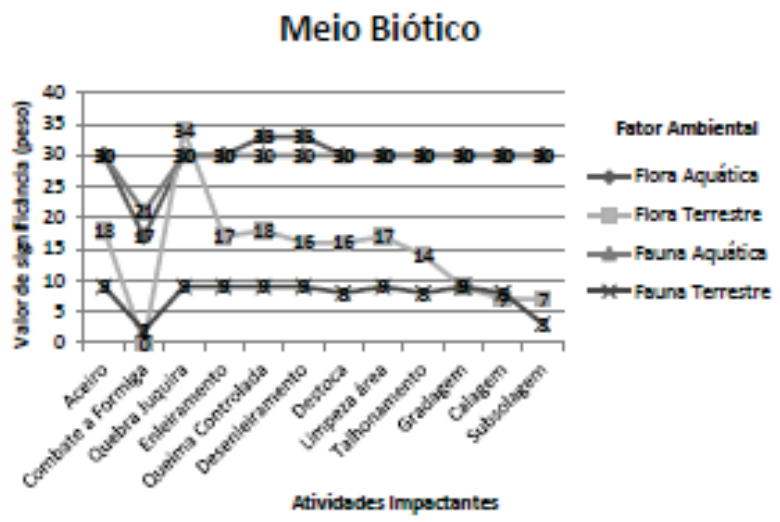

Figura 3 - Escala de significância sobre a flora e fauna aquática e terrestre.

Figure 3 - Scale of significance on aquatic and terrestrial flora and fauna.

\section{Meio socioeconômico}

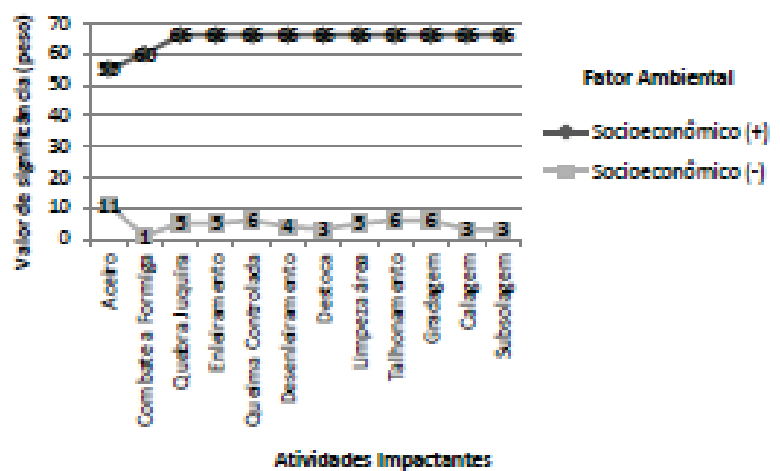

Figura 4-Escala de significância sobre o meio socioeconômico. Figure 4-Scale of significance on the socioeconomic environment.

desenleiramento, destoca e limpeza da área) e quatro (4) ao preparo do terreno (talhonamento, gradagem, calagem e subsolagem), as que demonstraram maiores pesos quando da soma total, considerando os fatores do meio (biofísico e socioeconômico), foram, respectivamente: $1^{\circ}$ - Quebra de juquira, com peso 238; $2^{\circ}$ - Queima controlada, com peso 235; $3^{\circ}$ - Talhonamento e Limpeza da Área, com peso 223 cada atividade; $4^{\circ}$ - Aeiro, Enleiramento e Desenleiramento, com peso 222 cada atividade; e $5^{\circ}$ - Gradagem, com peso 219. 
As demais atividades ficaram com pesos que somaram entre 105 e 208, demonstrando ser as oito atividades anteriormente citadas as que demandaram maiores atenções por parte do empreendedor em relação à definição de ações prioritárias em termos de gestão e, ou, manejo sustentável do meio quando da execução dessas atividades.

Em relação aos fatores ambientais biofísicos e socioeconômicos, apresentaram significância pequena em nível local os impactos que incidiram diretamente sobre a fauna terrestre e sobre o meio socioeconômico em relação aos impactos negativos (impacto visual e saúde humana). Impactos de significância pequena em nível regional foram evidenciados apenas quanto ao fator ambienta AR.

Apresentaram significância média, em nível local, os impactos que incidiram diretamente sobre o recurso edáfico e significância média em nível regional, os impactos que incidiram indiretamente sobre o recurso hídrico e, consequentemente, sobre a flora e fauna aquáticas.

Os impactos que incidiram diretamente sobre o meio socioeconômico apresentaram significância grande em nível regional e estão relacionados à geração de empregos, renda, capacitação da força de trabalho, desenvolvimento regional, histórico de ocupação e fixação do homem na terra.

\subsection{Checklist descritivo dos principais impactos ambientais}

\subsubsection{Impactos negativos}

- Depreciação da qualidade do ar pela emissão de partículas sólidas.

- Depreciação da qualidade do ar pela combustão na queima de resíduos vegetais.

- Exposição do solo a processos e, ou, fenômenos erosivos e a lavagem do solo que fica exposto aos intemperismos, após a erradicação da cobertura vegetal, sendo agravado, em algumas áreas, em relação à disposição do terreno.

- Ocupação de hábitat de fauna terrestre.

- Ocupação de hábitat de fauna aquática.

-.Contribuição ao assoreamento/turbidez dos canais de drenagem pela exposição do solo, acarretando partículas para esses canais.
- Impacto visual quando da erradicação da cobertura vegetal original.

- Impacto sobre a saúde humana em relação a ruídos, poeiras, produtos químicos.

- Impactos no banco de propágulos do solo quando do aquecimento do solo na queima controlada e no revolvimento e compactação pelo uso de implementos e maquinarias pesadas.

\subsubsection{Impactos positivos}

- Geração de informações sobre as áreas de influências diretas e indiretas do empreendimento, compilando informações de relevante interesse em níveis local, regional e estadual.

- Geração de emprego/renda e capacitação da força de trabalho que recebe treinamentos quanto ao uso de tecnologias relacionadas à captura e geração de dados geográficos.

- Capacitação da força de trabalho quanto ao uso dos implementos e máquinas e coleta de dados sobre o desenvolvimento dos plantios.

- Capacitação da força de trabalho quanto ao monitoramento ambiental das áreas diretas e indiretas dos plantios.

- A oferta de trabalho contribui para fixação do homem à terra e ao desenvolvimento regional.

- Disponibilidade de escolas, postos de saúde e áreas de lazer ao alcance dos trabalhadores.

\section{DISCUSSÃO}

As pesquisas sobre os impactos ambientais das atividades agroflorestais são baseadas no uso de indicadores de sustentabilidade. Esses indicadores, conforme trabalhos de Nantke (2001), são metodologias de pesquisa que buscam quantificar situações complexas, como o proposto para este estudo. Os objetivos principais foram a sistematização das informações e a seleção e consolidação de grandezas-chave. Para esse autor, o uso de indicadores é relevante para a elaboração de diagnósticos e planejamentos em longo prazo, tendo como principal vantagem a possibilidade de mostrar resultados de avaliações ambientais de forma simples aos responsáveis pela gestão florestal e, ou, ambiental. Almeida e Sánchez (2005), em seus trabalhos sobre 
monitoramento e avaliação de desempenho de revegetação de áreas de mineração, concluíram que uma das vantagens do uso de indicadores é que eles possibilitam a fácil compreensão e interpretação dos dados por parte de diferentes categorias de interessados, como empresários, agentes públicos e comunidade em geral.

Os resultados apresentados no item anterior demonstram que, no caso de florestas plantadas (com espécies de rápido crescimento), se devem desenvolver e, ou, buscar alternativas de manejo mais condizentes com a sustentabilidade. Nesse contexto, Lima (2006) referiu que se devem primeiro equacionar os aspectos básicos da produtividade florestal sob a perspectiva ecossistêmica, a fim de contribuir para a sustentabilidade da própria produtividade florestal, que é o objetivo primário dessas florestas. A caracterização e julgamento do significado do impacto ambiental, aqui feitos a partir da atribuição de valores construídos dentro de uma lógica definida, corroboraram Santos (2004), quando defendeu que nas avaliações de impacto ambiental se devem considerar o tipo de agente, o tipo de dano, a qualificação e, ou, quantificação de cada tipo de impacto e o compartimento ambiental afetado.

Em relação à definição dos critérios de significância, assim como os trabalhados por Moreira (1985), estes demonstraram que a ponderação do grau de significância de um impacto em relação ao fator ambiental afetado reflete a sua importância em nível ambiental. Dessa forma, pode ocorrer que determinado impacto, embora de magnitude elevada, não apresente tanta significância quando comparado com outros, no contexto de dada avaliação, como evidenciados através das análises das escalas de significância dos impactos sobre os recursos.

É relevante destacar que a formação de florestas plantadas em larga escala (assim como qualquer outro empreendimento considerado potencialmente impactante) requer a elaboração de estudos de impactos ambientais, pois entre os possíveis impactos ambientais estão os que dizem respeito aos recursos hídricos e edáficos. Nos resultados demonstrados neste estudo, ficaram evidentes que os impactos de maiores significâncias são os que recaem sobre os recursos edáficos, ainda que apenas em nível local e sobre os recursos hídricos, de maneira indireta, mas em nível regional.

Esses aspectos comungam com os observados por Couto et al. (2002), quando ressaltaram que é evidente que esses possíveis impactos ambientais não são inerentes às florestas plantadas em si, mas decorrem da interação do manejo com as condições do meio. Ou seja, os impactos podem ocorrer de forma mais intensa ou menos intensa, assim como podem ser minimizados pela adoção de estratégias de manejo que levem em conta as potencialidades e limitações do meio.

\section{CONCLUSÃO}

- O uso da matriz de interação permitiu a identificação dos impactos por meio impactado, bem como a visualização sistemática e hierarquizada das ações que provocam o maior número de impactos, além da identificação dos fatores ambientais mais e, ou, menos impactados e sua relevância e, ou, significância.

- Através da matriz, permitiu-se processar tanto variáveis qualitativas quanto quantitativas com possibilidade de abrangência de fatores ambientais biofísicos e socioeconômicos, além da demonstração dos resultados de forma compreensível e com caráter multidisciplinar.

- A aplicação da checklist descritiva permitiu identificar os principais impactos positivos e negativos de forma rápida e com baixo custo.

- A combinação e ponderação dos atributos permitiram abrangência maior da avaliação com uma visão macro das atividades e suas relações com os fatores ambientais.

- A maioria dos impactos apresenta significâncias médias local e regional.

- Os impactos de significância média regional e local deverão ser tratados prioritariamente.

- Todos os impactos surgem na etapa de implantação, estando ao alcance de identificação e definição de medidas minimizadoras e, ou, potencializadoras de gestão ambiental.

- É necessário que se instruam os processos de avaliação de impactos ambientais na rotina técnico-administrativa da empresa como instrumento de gestão ambiental.

\section{AGRADECIMENTOS}

Ao grupo Cikel Brasil Verde Madeiras Ltda., por permitir a realização das visitas técnicas, imprescindíveis à execução deste trabalho; e ao Conselho Nacional de Desenvolvimento Científico e Tecnológico (CNPq), pela concessão de bolsa de estudos.

Revista Árvore, Viçosa-MG, v.37, n.4, p.725-735, 2013 


\section{REFERÊNCIAS}

ALMEIDA, R. O. P. O.; SÁNCHEZ, L. E. Revegetação de áreas de mineração: critérios de monitoramento e avaliação do desempenho. Revista Árvore, v.29, n.1, p.47-54, 2005.

ANDREAZZI, M. A. R.; ANDRADE, R. M. Impactos das grandes barragens na saúde da população - uma proposta de abordagem metodológica para a Amazônia. In: FOREST'90, SIMPÓSIO INTERNACIONAL DE ESTUDOS AMBIENTAIS EM FLORESTAS TROPICAIS ÚMIDAS, Manaus. Anais... Rio de Janeiro: Biosfera, 1990.

ARRUDA, P. R. R. Avaliação qualitativa de impactos ambientais decorrentes de empreendimentos hidroelétricos. 2000. 117 f. Tese (Doutorado em Ciência Florestal) - Universidade Federal de Viçosa, Viçosa, MG, 2000.

BARBOSA, T. A. S.; DUPAS, F. A. Matriz simplificada para avaliar impactos ambientais em pequenas centrais Hidrelétricas ( $\mathrm{PCH})$. Revista Brasileira de Energia. v.12, n.2, p.125-139, 2006.

BRITO, E. R. Avaliação qualitativa de impactos ambientais decorrentes do empreendimento denominado “praias fluviais" no Estado de Tocantins. 2001. 124f. Dissertação (Mestrado em Ciência Florestal) - Universidade Federal de Viçosa, Viçosa, MG, 2001.

COUTO, L.; MULLER, M. D.; TSUKAMOTOFILHO, A. A. Florestas Plantadas para energia: aspectos técnicos, sócio-econômicos e ambientais. Viçosa, MG,Universidade Federal de Viçosa, Departamento de Engenharia Florestal, 2002.

CREPANI, E.; MEDEIROS, J. S.; PALMEIRA, A. F. Uso de técnicas de Sensoriamento Remoto e Geoprocessamento na proposta de um mapa de ordenamento territorial do Município de Paragominas (Estado do Pará).In:SIMPÓSIO BRASILEIRO DE SENSORIAMENTO REMOTO, 12.,2005, Goiânia. Anais...Goiânia:INPE, 2005.

FREITAS, L. C. et al. Avaliação quantitativa de impactos ambientais da colheita florestal em dois módulos. Revista Ceres, v.54, n.313, p.297-308, 2007.
LA ROVERE, E. L. Instrumentos de planejamento e gestão ambiental para a Amazônia, cerrado e pantanal: demandas e propostas: metodologia de avaliação de impacto ambiental. Brasília: IBAMA, 2001. 54p. (Série Meio Ambiente em Debate, 37).

LARA, P. T.; PETERS, E. L. Legislação Ambiental Federal - Os mais importantes diplomas legais do Brasil desde 1934 até 2004. 3.ed. Curitiba: Juruá, 2006.

LELLES, L. C. et al.Perfil ambiental qualitativo da extração de areia em cursos d' água. Revista Árvore, v.29, n.3, p.439-444, 2005.

LIMA, W. P. Efeitos hidrológicos do manejo de florestas plantadas. In: LIMA, W. P.; ZAKIA, M. J. B. As florestas plantadas e a água implementando o conceito de microbacia hidrográfica como unidade de planejamento. São Carlos: RiMa, 2006.

LIMA, W. P.; MENDES, C. A. B. Análise de Impactos Ambientais de florestas plantadas, no contexto de bacias hidrográficas: princípios norteadores. In: SEMINÁRIO DE RECURSOS HÍDRICOS DA BACIA HIDROGRÁFICA DO PARAÍBA DO SUL: O EUCALIPTO E O CICLO HIDROGRÁFICO, 1.,2007,

Taubaté.Anais...Taubaté:IPABHI, 2007. p.263-270.

LUDKE, R.L. Impactos ambientais da exploração florestal, em regime de manejo sustentável, praticada na várzea e na terra-firme, Estado do Amazonas - Brasil. 2000. 186p. Dissertação (Mestrado em Ciência Florestal) - Universidade Federal de Viçosa, Viçosa, MG, 2000.

MOREIRA, I. V. D. Avaliação de impacto ambiental. Rio de Janeiro: FEEMA, 1985.

NANTKE, H.J. Indicadores de Sustentabilidade e instrumentos de implementação das metas do Rio de Janeiro na Alemanha. In: HOFMEISTER, W.

Rio $+\mathbf{1 0}=$ Joanesburgo: rumo ao Desenvolvimento Sustentável. Fortaleza: Fundação Konrad Adenauer, 2001. p.97-116.

SANTOS, R. F. Planejamento ambiental: teoria e prática. São Paulo: Oficina de Textos, 2004. 
SILVA, E. Avaliação qualitativa de impactos ambientais do

reflorestamento no Brasil. 1994. 309f. Tese (Doutorado em Ciências Florestais) -

Universidade Federal de Viçosa, Viçosa, MG,1994.
STAMM, R. H. Método para avaliação de impacto ambiental em projetos de grande porte: estudo de caso de uma usina termelétrica. 2003. 284f. Tese (Doutorado em em Engenharia de Produção) -

Universidade Federal de Santa.Florianópolis: 2003. 
